\title{
I 034 Comparison of the presence of ischemic-type and non-ischemic-type delayed contrast enhancement and the presence of regional wall motion abnormalities detected by cardiac MRI in patients after heart transplantation
}

\author{
Constanze Merten*, Sonja Refle, Thomas J Dengler, Evangelos Giannitsis, \\ Hugo A Katus and Henning Steen
}

Address: University Hospital Heidelberg, Heidelberg, Germany

* Corresponding author

from I th Annual SCMR Scientific Sessions

Los Angeles, CA, USA. I-3 February 2008

Published: 22 October 2008

Journal of Cardiovascular Magnetic Resonance 2008, I0(SuppI I):AI59 doi:10.II86/I532-429X-I0-SI-AI59

This abstract is available from: http://jcmr-online.com/content/I0/SI/AI59

(c) 2008 Merten et al; licensee BioMed Central Ltd.

\section{Introduction}

Delayed contrast enhancement (DCE) of the ischemictype and non-ischemic type is frequently detected by cardiac magnetic resonance imaging (CMRI) in patients after heart transplantation (HTX). The relation between different enhancement patterns and regional wall motion abnormalities (rWMA) is unknown.

\section{Purpose}

We therefore sought to compare the presence of the two types of DCE and the association with rWMA in patients after HTX.

\section{Methods}

38 patients at a median interval of 81 months (range 12 to 201 months) after HTX underwent cMRI using a clinical 1.5 Tesla scanner for the assessment of DCE and regional left ventricular function. MR images were analysed following the 17-segment-model. Subendocardial and transmural DCE was classified as ischemic-type DCE. Intramural, spotted or diffuse DCE was classified as nonischemic-type DCE. Wall motion was visually assessed by consensus-reading by two experienced observers and classified as normokinetic, hypokinetic, akinetic or dyskinetic.

\section{Results}

Significant transplant coronary artery disease (TCAD) TCAD defined as coronary artery stenosis $>75 \%$ was present in 6 patients $(16 \%)$. Ischemic-type DCE was evident in 13 patients (34\%) and 27 segments respectively. In 17 of 27 segments (63\%) displaying ischemic-type DCE a rWMA was observed, in 10 of 27 (37\%) segments contractility was visually normal. We found a significant correlation between segments with Ischemic-type DCE and segments with rWMA $(\mathrm{r}=0.773, \mathrm{p}<0.0001)$. Nonischemic-type DCE was present 19 patients (50\%) and 53 segments respectively. Only $4(7.5 \%)$ of the affected 53 segments also showed rWMA. Consequently, no correlation was seen between segments with non-ischemic-type DCE and segments with rWMA $(r=0.068, \mathrm{p}=0.97)$. In 9 patients both types of DCE were observed, 6 of the 9 patients $(67 \%)$ also displayed rWMA in a total of $21 \mathrm{seg}$ ment. A total of 46 segments with rWMA were detected in 15 patients, whereof 4 patients did not show any type of DCE. Segmental analysis showed 25 of 46 segments (54\%) with impaired contractility in the absence of any type of DCE. Of the remaining 21 segments with rWMA 17 segments (81\%) displayed ischemic-type DCE; in only 4 segments with rWMA non-ischemic-type DCE was found. 


\section{Conclusion}

Ischemic-type DCE detected by cardiac MRI is a common finding in patients after HTX even in the absence of significant TCAD and is significantly associated with rWMA. Small subendocardial infarction may account for the absence of rWMA in some of the segments displaying ischemic-type DCE. In contrast, no correlation exists between the presence of non-ischemic-type DCE and rWMA. On the other hand, rWMA are frequently observed in the absence of DCE and could possibly be explained by hibernation of ischemic myocardium or rejection.

Publish with Bio Med Central and every scientist can read your work free of charge

"BioMed Central will be the most significant development for disseminating the results of biomedical research in our lifetime. " Sir Paul Nurse, Cancer Research UK

Your research papers will be:

- available free of charge to the entire biomedical community

- peer reviewed and published immediately upon acceptance

- cited in PubMed and archived on PubMed Central

- yours - you keep the copyright

Submit your manuscript here:

http://www.biomedcentral.com/info/publishing_adv.asp 